\title{
The Pathway of Intraseasonal Wave Energy in the Tropical Indian Ocean as Identified by a Seamless Diagnostic Scheme
}

\author{
Tomomichi Ogata ${ }^{1}$ and Hidenori Aiki ${ }^{2,1}$ \\ ${ }^{1}$ Japan Agency for Marine-Earth Science and Technology, Yokohama, Japan \\ ${ }^{2}$ Institute for Space-Earth Environmental Research, Nagoya University, Nagoya, Japan
}

\begin{abstract}
This study makes a first attempt to apply the diagnostic scheme of Aiki et al. (2017) to the output of an ocean general circulation model (OGCM), in order to investigate the basin-wide pathway of equatorial and mid-latitude wave energy associated with intraseasonal variability in the Indian Ocean. The vertical mode decomposition shows that 90-day variability of the second baroclinic mode is dominant in a realistic OGCM experiment. For 90-day equatorial Kelvin wave (KW) and Rossby wave (RW), energy input by wind stress appears in the eastern equatorial Indian Ocean that is then transferred eastward by KWs along the eastern equatorial waveguide (while westward as RW off equator). For 30-day Mixed-Rossby Gravity waves (MRG), wave energy is transferred eastward while wave phase propagates westward that is consistent with the dispersion relationship of low-frequency MRG. The new diagnostic scheme is able to show, particularly for 30-day MRG, eastward energy fluxes along the equatorial waveguide, while the other schemes in previous studies (e.g. pressure flux, quasi-geostrophic flux) cannot show the direction of the group velocity of equatorial waves.
\end{abstract}

(Citation: Ogata, T., and H. Aiki, 2019: The pathway of intraseasonal wave energy in the tropical Indian Ocean as identified by a seamless diagnostic scheme. SOLA, 15, 262-267, doi:10.2151/ sola.2019-047.)

\section{Introduction}

Shallow water system on an equatorial $\beta$-plane is a simple but essential framework to describe atmospheric and oceanic phenomena in tropical regions. For example, Matsuno (1966) derived a set of analytical solutions for the shallow water system as equatorial Kelvin wave (KW), Mixed-Rossby Gravity wave (MRG), Rossby wave (RW) and inertial gravity wave (IGW). Gill (1980) derived atmospheric response to localized diabatic heating. Such steady response is known as "Matsuno-Gill response" (Matsuno 1966; Gill 1980) and this solution captures realistic atmospheric response during El-Niño events (e.g. Zebiak 1982; Rasmusson and Wallace 1983). The analytical solutions of equatorial KW, MRG, RWs and IGWs are also seen in the realistic ocean as a response to wind forcing. For example, equatorial westerly wind anomaly over the central equatorial Pacific generates a KW (RW) response in the eastern (western) basin during El-Niño events (e.g. McCreary and Anderson 1984; Schopf and Suarez 1988). Spectrum analysis of observed outgoing longwave radiation and sea surface height also shows that these equatorial waves (KW, MRG, RWs and IGWs) characterize the equatorial atmospheric and oceanic dynamics (e.g. Wheeler and Kiladis 1999; Wakata 2007). Thus, most of planetary-scale phenomena around the equator can be interpreted in terms of solutions to the shallow water equations.

To identify the synoptic pathway of wave energy/activity in the atmosphere and ocean, two separate approaches have been proposed in the literature; one is "ray-tracing" approach (e.g. Hoskins and Karoly 1981, McCreary 1984) and another is "Eliassen-Palm (EP) flux" approach (e.g. Andrews 1987; Buhler 2014). A major difference between the two approaches is whether the information of wavenumber and wave frequency is necessary ("ray-tracing" approach) or not ("EP flux" approach) in the course of analysis. As a diagnosis tool for the direction of the group velocity of waves, the EP flux has been widely used in the literature noting that; 1) it does not rely on a Fourier analysis and 2) its convergence interacts with the momentum budget of mean flows (e.g. Greatbatch et al. 2018). The EP flux is closely linked to the three-dimensional flux of wave activity, which has been first shown for mid-latitude Rossby wave using the quasi-geostrophic framework (Hoskins et al. 1983; Plumb 1986; Takaya and Nakamura 1997). For midlatitude waves, Miyahara (2006) and Kinoshita and Sato (2013) have shown a similar link between the EP flux and the group velocity in a three-dimensional framework, without relying on the quasi-geostrophic wave-activity equation. The global mapping of the transfer of wave energy has been little illustrated in previous studies except for IGW in the ocean using $\left\langle\overline{\left\langle u^{\prime} p^{\prime}\right.}, \overline{v^{\prime} p^{\prime}}\right\rangle^{1}$ (Niwa and Hibiya 2004; Furuichi et al. 2008), which we refer to as "pressure flux".

However, pressure flux is not suitable for detecting the pathway of RWs because the flux is not parallel to the group velocity of RWs. Alternatively, Orlanski and Sheldon (1993) derived an expression for calculating the energy flux that is applicable to the RWs. However, their expression could not be applicable to equatorial regions. Recently Aiki et al. (2017, hereafter AGC17) have derived, using a shallow-water equation system, a seamlessly diagnosable expression for the energy flux of waves at all latitudes. This new scheme has three distinct features; 1) it can point in the direction of the group velocity of both planetary and gravity waves, 2) it is applicable to all types of equatorial waves with no singularity at the equator, and 3 ) it satisfies the boundary condition at coastlines. For example, the new diagnostic scheme can illustrate an exact energy pathway associated with the connection of the equatorial and coastal waveguides, which may allow for oceanic tropical-extratropical interactions to be quantified in terms of energy transfers. This has been preliminarily demonstrated in AGC17 for interannual waves in a single-layer model experiment. A next step is to apply the new diagnostic scheme to waves at higher frequencies that are associated with dominant variations in the tropical ocean. In the equatorial Indian Ocean, there are several intraseasonal variations in addition to seasonal and interannual variations (e.g. Vinayachandran et al. 1999; Horii et al. 2008; Iskandar et al. 2009; Nagura and McPhaden 2010), For example, the energy pathways of 90-day (e.g. Han 2005; Iskandar et al. 2006), 30-day (e.g. Kindle and Thompson 1989; Iskandar et al. 2005; Chatterjee et al. 2013) and 15-day (e.g. Sengupta et al. 2001; Ogata et al. 2008; Horii et al. 2011; Chatterjee et al. 2013) waves in the Indian Ocean have not been clarified in the previous studies. In this study, using the new seamless diagnostic scheme, the basin-wide pathways of equatorial and mid-latitude wave energy associated with intraseasonal variability in the Indian Ocean are investigated. 


\section{Methodology and brief description of OGCM experiment}

We converted from 3D-field to 2D-field using vertical mode decomposition as follows,

$$
\begin{aligned}
& \partial_{z}\left(\frac{1}{N^{2}} \partial_{z} \psi_{m}\right)=-\frac{1}{c_{m}^{2}} \psi_{m}, \\
& p^{\prime}(x, y, z, t)=\sum_{m} p_{m}(x, y, t) \psi_{m}(z), \\
& u^{\prime}(x, y, z, t)=\sum_{m} u_{m}(x, y, t) \psi_{m}(z), \\
& v^{\prime}(x, y, z, t)=\sum_{m} v_{m}(x, y, t) \psi_{m}(z),
\end{aligned}
$$

where $\psi_{m}=\psi_{m}(z)$ and $c_{m}$ are the eigenfunction and gravity wave speed of $m$-th vertical mode. Using (1a), we derived top-10 eigen modes $\left(c_{m}\right)$ and functions $\left(\psi_{m}\right)$ with boundary condition of $\partial_{z} \psi_{m}=$ 0 at top and bottom $(z=5500 \mathrm{~m})$ and $\psi_{m}(z)=1$ at the top $(z=0)$. Substitution of (1b)-(1d) to the governing equations (A1a)-(A1c) and projection to each vertical mode yields

$$
\begin{aligned}
& \partial_{t} u_{m}-f v_{m}=-\partial_{x} p_{m}, \\
& \partial_{t} v_{m}+f u_{m}=-\partial_{y} p_{m}, \\
& \partial_{t} p_{m}+c_{m}^{2}\left(\partial_{x} u_{m}+\partial_{y} v_{m}\right)=0,
\end{aligned}
$$

which constitute a shallow-water equation system (see Supplement-A for details).

\subsection{Previous schemes for diagnosing the energy flux}

The decomposed 2D-field enables us to use expressions for computing the 2D-energy flux for a given vertical mode. For IGW, the basin-scale pathways of wave energy may be easily diagnosed from model outputs using the pressure flux,

$$
F_{m}^{P}=\left\langle\overline{u_{m} p_{m}}, \overline{v_{m} p_{m}}\right\rangle,
$$

where the overbar symbol denotes a low-pass temporal filter. Equation (3a) has been used to trace the group-velocity-based pathways of tidal and wind-induced IGW energy (Niwa and Hibiya 2004; Furuichi et al. 2008). On the other hand, for mid-latitude RW, the pressure flux (3a) does not point in the direction of group velocity. Using the quasi-geostrophic equation system appropriate for RW, Longuet-Higgins (1964) and Orlanski and Sheldon (1993, hereafter OS93) have derived an expression for the rotational flux that may be added to the pressure flux:

$$
F_{m}^{O S}=F_{m}^{P}+\left\langle\partial_{y}\left[\overline{p_{m}^{2}} /(2 f)\right],-\partial_{x}\left[\overline{p_{m}^{2}} /(2 f)\right]\right\rangle,
$$

where $f$ is the Coriolis parameter. However (3b) does not satisfy the boundary condition at coastlines and also becomes singular at the equator owing to the presence of the Coriolis parameter in the denominator.

\subsection{The diagnosis scheme of AGC17}

To overcome the difficulties of the quasi-geostrophic framework, AGC17 have proposed a seamlessly diagnosable expression for the energy flux for waves in a shallow-water equation system at all latitudes, as explained below. The cornerstone of the formulation of $\mathrm{AGC} 17$ is the derivation of a new inversion equation for Ertel's potential vorticity $(\mathrm{EPV})^{2}$

$$
\begin{gathered}
{\left[\partial_{x x}+\partial_{y y}-f^{2} / c_{m}^{2}-\left(3 / c_{m}^{2}\right) \partial_{t t}\right] \varphi_{m}} \\
\quad=\partial_{x} v_{m}-\partial_{y} u_{m}-\left(f / c_{m}^{2}\right) p_{m}
\end{gathered}
$$

Using the solution $\varphi_{m}$ of (4a), AGC17 have shown an exact expres- sion for calculating the group-velocity-based energy flux to read

$$
\begin{aligned}
F_{m}^{A G C-L 0}=F_{m}^{P}+ & \left\langle\partial_{y}\left[\overline{p_{m} \varphi_{m}} / 2+\overline{\left(\partial_{t t} u_{m}\right) \varphi_{m}} / \beta\right],\right. \\
& \left.-\partial_{x}\left[\overline{p_{m} \varphi_{m}} / 2+\overline{\left(\partial_{t t} u_{m}\right) \varphi_{m}} / \beta\right]\right\rangle,
\end{aligned}
$$

which involves no singularity at the equator and has been referred to as Level-0 expression. This new diagnostic scheme is applicable to both RW and GW at all latitudes (including equatorial waves) and satisfies the boundary condition at coastlines where $\varphi_{m}$ $=0$ is set.

In order to mitigate difficulty associated with the second-order time-derivative term on the left hand side of the exact inversion equation (4a), AGC17 have investigated the consequence of simplifying (4a) to read,

$$
\left[\partial_{x x}+\partial_{y y}-f^{2} / c_{m}^{2}\right] \varphi_{m}^{a p p}=\partial_{x} v_{m}-\partial_{y} u_{m}-\left(f / c_{m}^{2}\right) p_{m},
$$

which turns out to be identical to the traditional inversion equation for EPV. The solution $\varphi_{m}^{a p p}$ of (5a) has been used in AGC17 to approximate the exact expression for the energy flux $F_{m}^{A G C-L 0}$ to read,

$$
\begin{aligned}
F_{m}^{A G C-L 1}=F_{m}^{P}+ & \left\langle\partial_{y}\left[\overline{p_{m} \varphi_{m}^{a p p}} / 2+\overline{\left(\partial_{t t} u_{m}\right) \varphi_{m}^{a p p}} / \beta\right],\right. \\
& \left.-\partial_{x}\left[\overline{p_{m} \varphi_{m}^{a p p}} / 2+\overline{\left(\partial_{t t} u_{m}\right) \varphi_{m}^{a p p}} / \beta\right]\right\rangle, \\
F_{m}^{A G C-L 2}=F_{m}^{P}+ & \left\langle\partial_{y}\left(\overline{p_{m} \varphi_{m}^{a p p}} / 2\right),-\partial_{x}\left(\overline{p_{m} \varphi_{m}^{a p p}} / 2\right)\right\rangle,
\end{aligned}
$$

that have been referred to as Level-1 and Level-2, respectively.

\subsection{OGCM experiments}

In this study, we used an eddy-resolving realistic OGCM experiment so-called OFES hindcast run (Masumoto et al. 2004; 2010), which cover a near global domain from $75^{\circ} \mathrm{S}$ to $75^{\circ} \mathrm{N}$ with high resolution of 0.1 degree in the horizontal direction (in both longitude and latitude), and there are 54 vertical levels. After a 48-year spin-up, a hindcast integration was executed from 1948 to present using the NCEP daily mean forcing (hereafter OFES NCEP; Masumoto et al. 2004; Sasaki et al. 2008). The 3-day output from 1998 to 2015 in the OFES_NCEP experiment was used in the present study.

\section{Energy pathway in the tropical Indian Ocean}

The diagnostic schemes have been formulated using the shallow water system, while OGCM outputs are in three-dimensional coordinates. From OGCM outputs, 3D horizontal velocity and pressure (derived from density) fields are projected onto "equivalent shallow water" 2D field using the vertical mode decomposition in Section 2 (gravity wave speed $c_{n}$ for each vertical mode is shown in Table 1). Decomposed 2D field suggests that the second mode is dominant in 90-day variability (second mode explains about $40-50 \%$ of total from Fig. S1). From Table 1 and Supplement-B, differences associated with zonal locations are small in a sense of similar gravity wave speed $\left(c_{m}\right)$ and second mode dominance of wind coupling coefficient $\left(H_{m}=\int \psi_{m}^{2} d z\right)$. In vertical mode projection of OGCM output (see Supplement-C for details), second mode is dominant in upper (Fig. S3a) and subsurface layer (Fig. S3b), while first mode also has modest contribution in the upper ocean. In the 90-day variability, we focus on the second mode and discuss about contribution of the first mode in Fig. 3.

\footnotetext{
${ }^{2}$ The right hand side of (4a) may be regarded as the linearized version of EPV understanding $f H / h=f /[1+(h-H) / H] \approx f[1-(h-H) / H]=$ $f\left(1-p_{m} / c_{m}^{2}\right)$ where $h$ and $H$ are layer thickness and the reference constant of it, respectively. One of the reasons why AGC17 have used the term EPV is to avoid confusion with quasi-geostrophic potential vorticity, $\left(\partial_{x x}+\partial_{y y}-f^{2} / c^{2}\right)\left(p_{m} / f\right)$, that has been sometimes used in the classical literature.
} 
Table 1. Gravity wave speed as eigen value of each mode $\left(c_{m}: \mathrm{m} \mathrm{s}^{-1}\right)$ and wind coupling coefficient $\left(H_{m}=\int \psi_{m}^{2} d z: \mathrm{m}\right)$ at western IO $\left(0^{\circ} \mathrm{N} 50^{\circ} \mathrm{E}\right)$, central IO $\left(0^{\circ} \mathrm{N} 70^{\circ} \mathrm{E}\right)$, eastern $\mathrm{IO}\left(0^{\circ} \mathrm{N} 90^{\circ} \mathrm{E}\right)$, and zonal averaged profile (eqIO).

\begin{tabular}{|c|c|c|c|c|}
\hline mode number & $\begin{array}{c}c_{m} \\
\left(0^{\circ} \mathrm{N} 50^{\circ} \mathrm{E}\right)\end{array}$ & $\begin{array}{c}H_{m} \\
\left(0^{\circ} \mathrm{N} 50^{\circ} \mathrm{E}\right)\end{array}$ & $\begin{array}{c}c_{m} \\
\left(0^{\circ} \mathrm{N} 70^{\circ} \mathrm{E}\right)\end{array}$ & $\begin{array}{c}H_{m} \\
\left(0^{\circ} \mathrm{N} 70^{\circ} \mathrm{E}\right)\end{array}$ \\
\hline $1 \mathrm{st}$ & 2.48 & 309.7 & 2.48 & 268.0 \\
\hline 2nd & 1.49 & 132.2 & 1.54 & 122.4 \\
\hline $3 \mathrm{rd}$ & 0.89 & 2099.6 & 0.87 & 1613.6 \\
\hline 4th & 0.61 & 1267.0 & 0.60 & 275.8 \\
\hline 5 th & 0.51 & 285.2 & 0.52 & 288.9 \\
\hline mode number & $\begin{array}{c}c_{m} \\
\left(0^{\circ} \mathrm{N} 90^{\circ} \mathrm{E}\right)\end{array}$ & $\begin{array}{c}H_{m} \\
\left(0^{\circ} \mathrm{N} 90^{\circ} \mathrm{E}\right)\end{array}$ & $\begin{array}{c}c_{m} \\
(\mathrm{eqIO})\end{array}$ & $\begin{array}{c}H_{m} \\
\text { (eqIO) }\end{array}$ \\
\hline $1 \mathrm{st}$ & 2.53 & 228.0 & 2.50 & 262.1 \\
\hline 2 nd & 1.64 & 132.4 & 1.56 & 127.6 \\
\hline $3 \mathrm{rd}$ & 0.92 & 2462.8 & 0.89 & 2014.2 \\
\hline 4th & 0.65 & 809.7 & 0.61 & 514.1 \\
\hline 5th & 0.57 & 273.2 & 0.53 & 251.6 \\
\hline
\end{tabular}

\subsection{0-day variability}

Han (2005) showed that the 90-day variability of zonal current in the equatorial Indian Ocean is resonantly excited by intraseasonal wind forcing. Iskandar et al. (2006) pointed out that such 90-day intraseasonal equatorial $\mathrm{KW}$ also generates coastal current variability along Sumatra and Java as coastal KW. As a dominant intraseasonal variability in the equatorial Indian Ocean, we have investigated the 90 -day variability. It should be noted that time derivative term in EPV inversion is almost negligible in 90-day variability from approximated AGC-L2 $\left(\varphi_{m}^{a p p}\right.$, Eq. (5a)) and exact AGC-L0 $\left(\varphi_{m}\right.$, Eq. (4a)) in Fig. S4, and therefore AGC-L2 framework is enough for energy flux diagnosis of 90-day variability.

Figures $1 \mathrm{a}, 1 \mathrm{~b}$, and 1c shows horizontal current and pressure with 90-day (78-108 day band-passed) variability of second baroclinic mode in May-July 2000 of the OFES NCEP experiment. On 01 May 2000 (Fig. 1a), equatorial RW with cyclonic twinvortex, negative pressure anomaly, and equatorial westerly appears in the central Indian Ocean (around $60^{\circ} \mathrm{E}-80^{\circ} \mathrm{E}$ ). In the eastern part (east of $80^{\circ} \mathrm{E}$ ), positive pressure anomaly implies that there is superposition of KW and reflected RW responses. After that, on 01 June 2000 (Fig. 1b), negative pressure anomaly associated with equatorial RW moves to the western Indian Ocean (west of $60^{\circ} \mathrm{E}$ ). In the eastern part (east of $80^{\circ} \mathrm{E}$ ), positive pressure anomaly moves westward, suggesting clear reflected RW response. On 01 July 2000 (Fig. 1c), equatorial RW with anticyclonic twin-vortex, positive pressure anomaly, and equatorial easterly appear in central Indian Ocean (around $60^{\circ} \mathrm{E}-80^{\circ} \mathrm{E}$ ). In the eastern part (east of $80^{\circ} \mathrm{E}$ ), negative pressure anomaly implies that there is superposing of KW and reflected RW responses. That is almost opposite phase to Fig. 1a. We calculate energy fluxes as a long-term mean in 1998-2015 (Fig. 2). Pressure flux (Fig. 2a) show westward vector off equator around $2^{\circ} \mathrm{S}$ and $2^{\circ} \mathrm{N}$ from flux divergence (energy input) around $80^{\circ} \mathrm{E}$. OS93 flux (Fig. 2b) also shows westward vector but flux is not applicable on the equator. From result of Fig. 2c, the new scheme (AGC-L2 flux) seems to capture the energy input around $80^{\circ} \mathrm{E}$ and energy propagation along the equatorial waveguide as eastward energy propagation by $\mathrm{KW}$, and westward energy propagation by RW off equator.

90-day variability is thought of as being significantly excited variability by intraseasonal wind forcing (e.g. Han 2005). To confirm this, we show in Fig. 3 the distributions of wind forcing and AGC-L2 energy flux. Zonal distribution of standard deviation of 90-day (78-108 day band-passed) zonal wind stress variability on the equator (Fig. 3a) shows 90-day wind forcing locating in the equatorial Indian Ocean broadly, but has a peak around $80^{\circ} \mathrm{E}$. AGC-L2 flux and its convergence/divergence (Fig. 3b) imply that energy input (flux-divergence) appears around $80^{\circ} \mathrm{E}$ and its energy is transferred eastward by $\mathrm{KW}$, which is consistent with Fig. 3a. Around $55^{\circ} \mathrm{E}-70^{\circ} \mathrm{E}$, the westward energy transfer by RW seems (a)

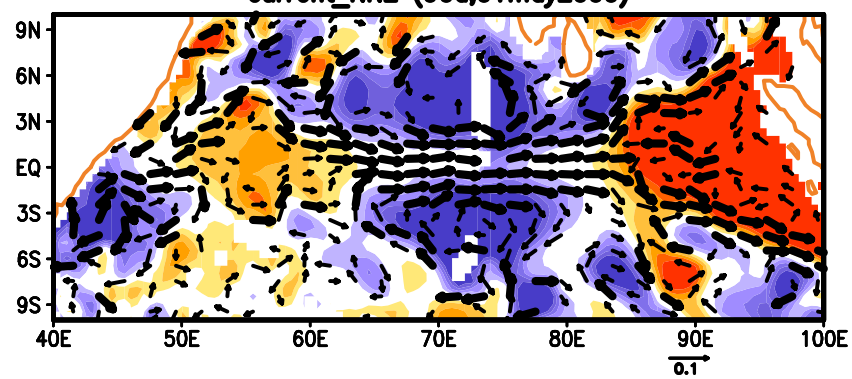

(b)

current_NN2 (90d,01jun2000)

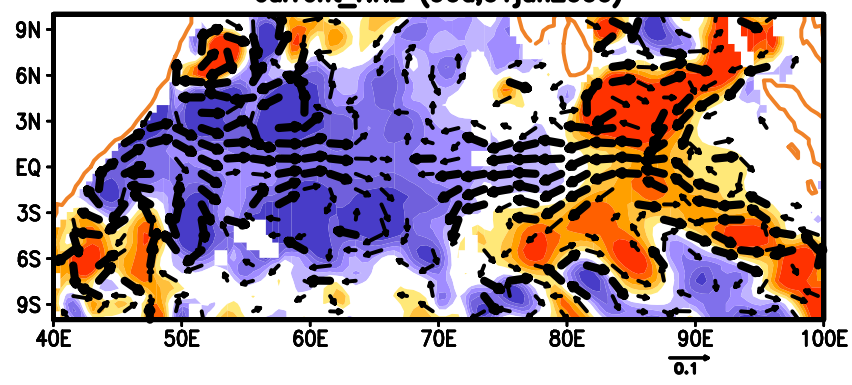

(c)

current_NN2 (90d,01jul2000)

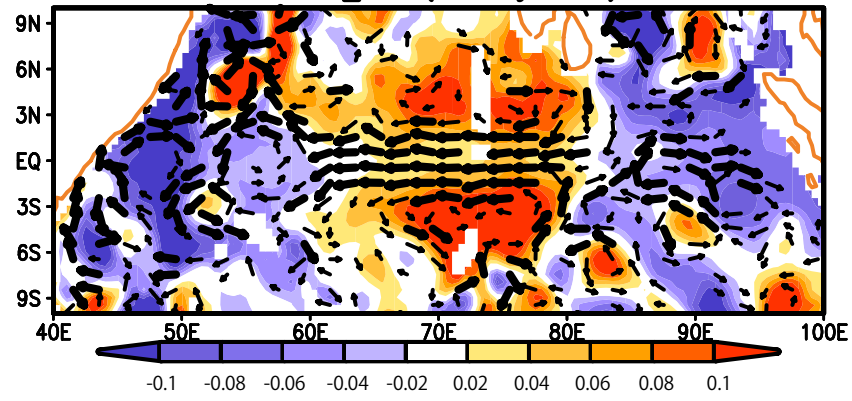

Fig. 1. Snapshot of $u, v$ (arrows), $p$ (color shading) for the second baroclinic mode associated with 90-day (78-108 day band-passed) variability in the OFES_NCEP experiment. The magnitude of velocity is indicated by either the length of arrows (for ranges less than $0.05 \mathrm{~m} \mathrm{~s}^{-1}$ ) or thicker arrows with a constant length (for greater ranges).

stronger south of equator $\left(3^{\circ} \mathrm{S}\right)$. In contrast, in the eastern part (east of $80^{\circ} \mathrm{E}$ ), westward energy flux by RW seems stronger north of equator $\left(3^{\circ} \mathrm{N}\right)$.

Figure 3 also shows contribution of first baroclinic mode for energy flux (Fig. 3c). Compared to second mode contribution (Fig. $3 b)$, first mode contribution is small. It is consistent with previous studies (Han 2005; Iskandar et al. 2006) that basin-wide resonance and small wind coupling coefficient $\left(H_{m}\right)$ favor the second mode dominance in 90-day variability. It should be noted that zonal difference of $H_{m}$ due to sharp (weak) thermocline in the east (west) may modulate the ratio of the second mode contribution (e.g. Iskandar et al. 2006).

\subsection{0-day variability of MRG}

In addition to the 90-day variability, significant intraseasonal variability of MRG has been shown in previous studies as 15-day and 30-day variability (e.g. Kindle and Thompson 1989; Sengupta et al. 2001; Ogata et al. 2008; Ogata et al. 2017). In this study, we focus on the 30-day variability in OFES_NCEP. From Figs. S3d and S5, 30-day variability can be almost explained by combination of first and second modes (both mode has about 20-30\% contribution in KE; see also Supplement-C for details). Therefore we considered energy flux as sum of first and second baroclinic modes. Figures 4 and 5 show 30-day variability (24-36 day bandpassed) and energy fluxes in OFES_NCEP. From western bound- 
(a)

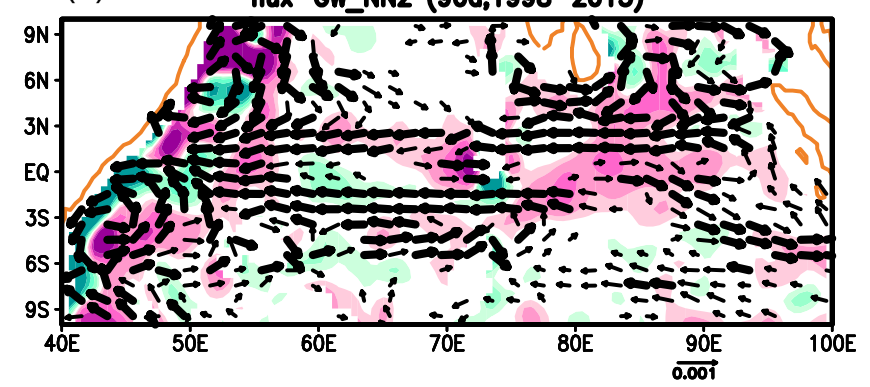

(b)

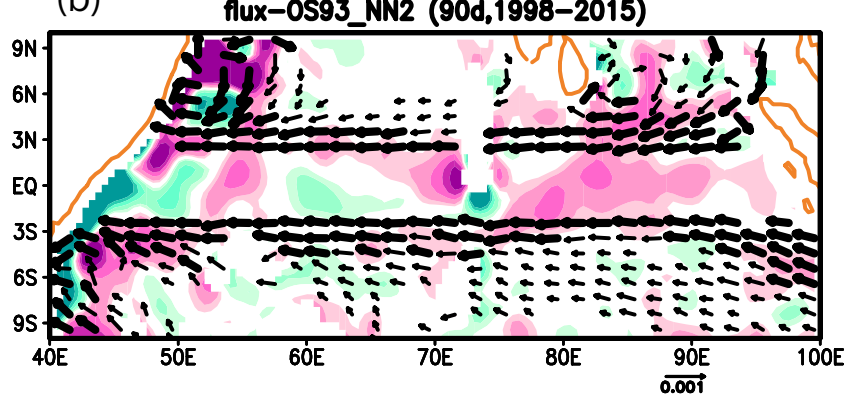

(c)

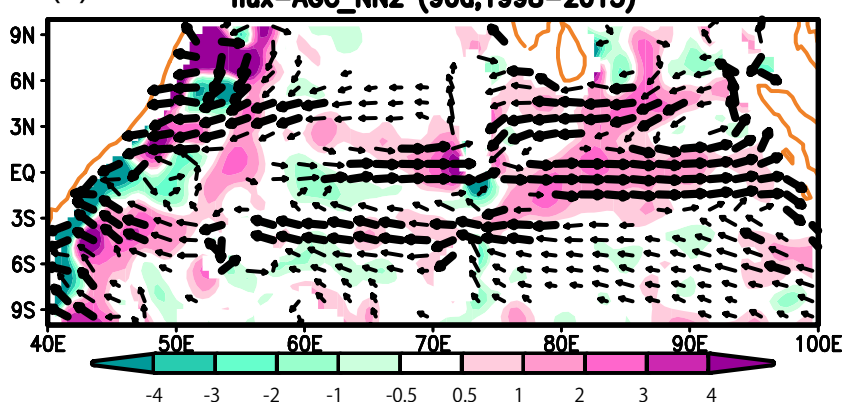

Fig. 2. Energy flux of the second baroclinic mode (arrows) and its horizontal divergence (color shading) associated with 90-day (78-108 day bandpassed) variability in the OFES_NCEP experiment, as estimated using (a) the pressure flux scheme, (b) Orlanski and Sheldon (1993) scheme, and (c) Aiki et al. (2017) scheme. The magnitude of the energy flux is indicated by either the length of arrows (for ranges less than $0.0005 \mathrm{~m}^{3} \mathrm{~s}^{-3}$ ) or thicker arrows with a constant length (for greater ranges).

ary, MRG and short Rossby wave can be excited (Figs. 4a, 4b, and $4 \mathrm{c}$ ), which shows westward phase propagation and eastward energy propagation. On the other hand, KW shows eastward propagation in central and eastern basin. Consistent with this, energy flux (pressure flux and AGC17) shows eastward vector (Figs. 5a, 5b, and 5c). Particularly, AGC17 flux shows equatorward and eastward energy propagation from divergence around western boundary (Fig. 5c) more adequately. It should be noted that these waves at the western boundary are generated by internal instability and therefore improvement of energy flux including mean-shear flow effect will be needed.

\section{Summary}

To overcome problems at the equator, AGC17 proposed a seamless diagnostic scheme for the group-velocity-based energy flux with the inversion of Ertel's potential vorticity (EPV). This new scheme has two distinct features; 1) applicable to both Rossby wave (RW) and gravity wave (GW) at all latitudes, 2) applicable to all types of equatorial waves. In this study, we have applied this new seamless scheme to the intraseasonal variability in the equatorial Indian Ocean using in a realistic OGCM experi- (a)

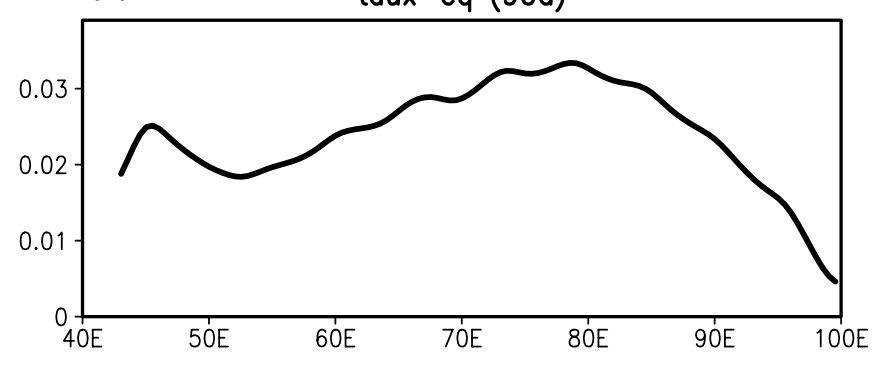

(b) flux-AGC_NN2 (90d,1998-2015)

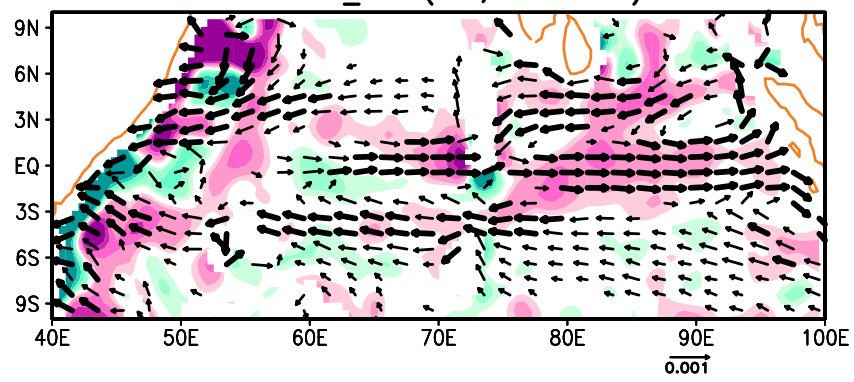

(c)

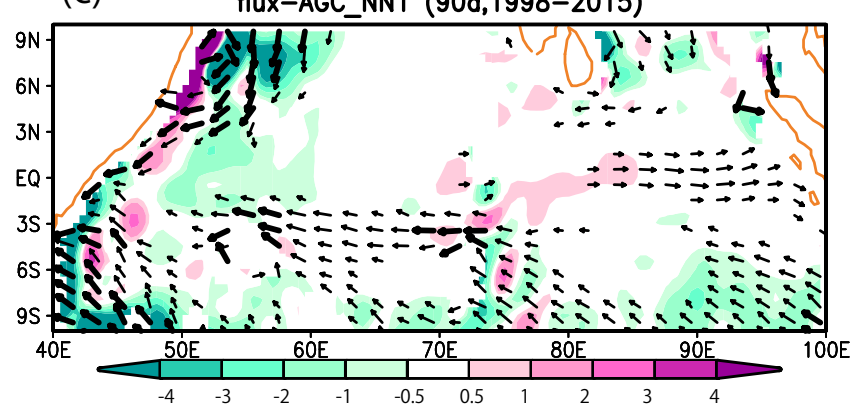

Fig. 3. (a) Standard deviation of zonal wind stress $\left(\mathrm{N} \mathrm{m}^{-1}\right)$ with 90 -day (78-108 day band-passed) variability as long-term mean for 1998-2015 in the OFES_NCEP experiment. (b) AGC17 Level-2 flux associated with the second baroclinic mode (arrows with a unit of $\mathrm{m}^{3} \mathrm{~s}^{-3}$ ) and its horizontal divergence (color shading with a unit of $10^{-8} \mathrm{~m}^{2} \mathrm{~s}^{-3}$ ) as long-term mean for 1998-2015. (c) Same as (b) but for the first baroclinic mode.

ment.

First, we investigated features of the approximate version of the new scheme, referred to as Level-2 in AGC17. Energy diagnosis of 90-day variability by equatorial KW and RW shows that energy input appears in the eastern basin (around $80^{\circ} \mathrm{E}$ ). In a long-term mean (1998-2015), the new seamless flux captures an eastward energy transfer by KW and RW along the equatorial waveguide. On the other hand, first mode contribution was small in energy transfer for 90-day variability. Furthermore, the new seamless flux for 30-day MRG shows eastward vector with its maximum locating at the equator, while the other schemes in previous studies (e.g. pressure flux, OS93 flux) cannot represent the group-velocity-based energy transfer adequately.

Future studies should investigate the sensitivity of different levels of the diagnostic scheme of AGC17 to near-inertial equatorial waves, and should develop a new formulation with sheared mean flows. It should be noted that, in a perspective of atmospheric dynamics, the new formulation with sheared mean flows is also a challenging theme to clarify mid-latitude forcing (such as PV intrusion of cold surge) of equatorial waves (such as MRG and RW) and vice versa (e.g. Matthews and Kiladis 2000; Fukutomi and Yasunari 2002; Fukutomi and Yasunari 2013). 
(a)

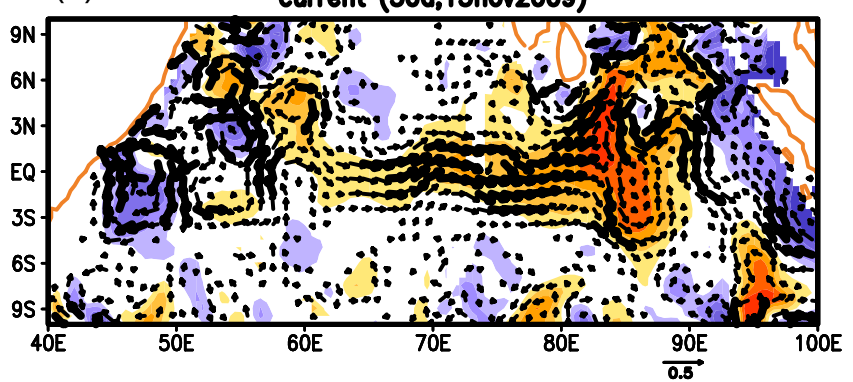

(b)

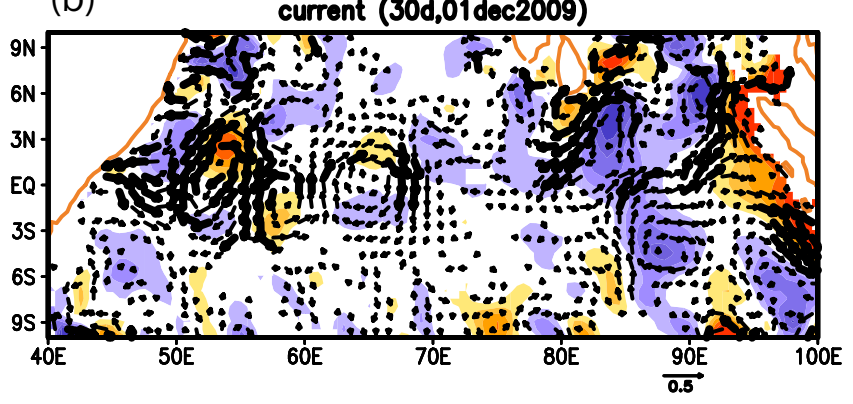

(c)

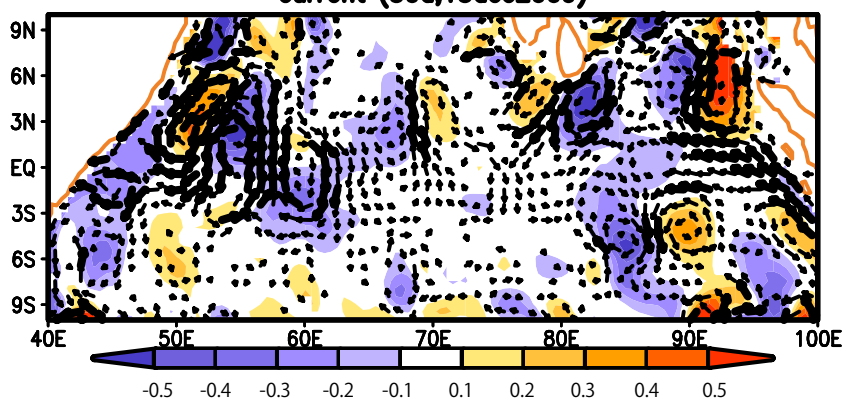

Fig. 4. Same as Fig. 1 but for 30-day variability in OFES_NCEP (sum of first and second baroclinic modes). The magnitude of velocity is indicated by either the length of arrows (for ranges less than $0.25 \mathrm{~m} \mathrm{~s}^{-1}$ ) or thicker arrows with a constant length (for greater ranges).

\section{Acknowledgements}

Numerical experiments of OFES were executed on the Earth Simulator of the Japan Agency for Marine-Earth Science and Technology (JAMSTEC). This work was supported by Grant for Environmental Research Projects from The Sumitomo Foundation (FY2017, No.173070), and KAKENHI by MEXT (18H03738).

Edited by: H. Tsujino

\section{Supplements}

Supplement-A explains the vertical mode decomposition used in the present study. Supplement-B is about sensitivity of zonal difference in stratification. Interpretation of vertical mode projection in the equatorial IO is also discussed in Supplement-C. Figure S1 shows the decomposed 90-day 2D field of OFES_NCEP output. Figures S2 shows vertical profiles of both Brunt-Vaisala frequency $(N)$ and eigen function $\left(\psi_{m}\right)$. Figure S3 shows standard deviation of vertical mode decomposed intraseasonal variability on the equator. Comparison of the EPV-inverted functions of AGC-L2 and AGC-L0 is shown in Fig. S4. Figure S5 shows the decomposed 2D field of 30-day variability.

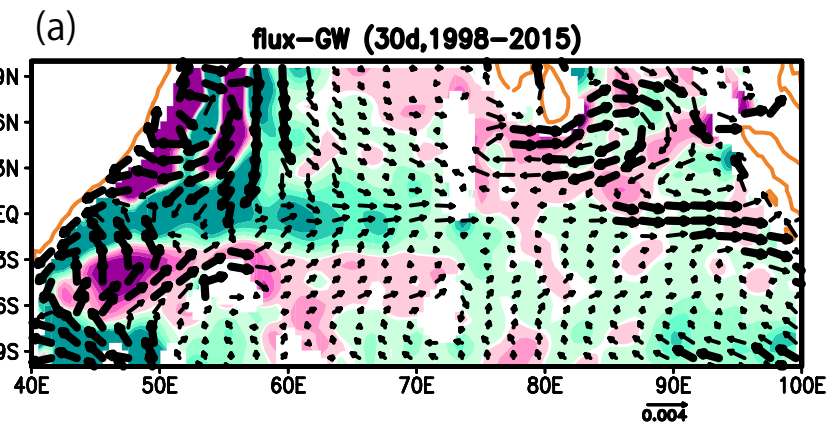

(b)

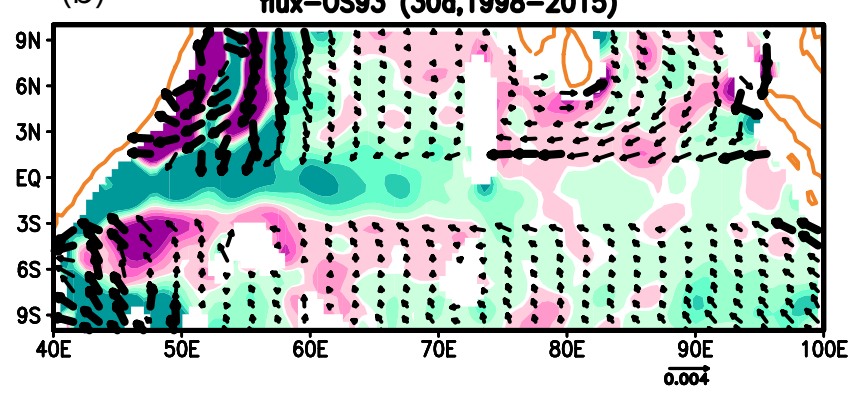

(c)

flux-AGC (30d,1998-2015)

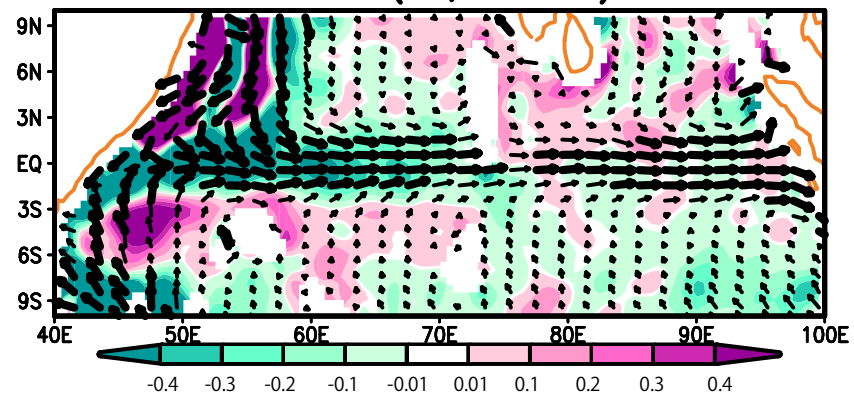

Fig. 5. Same as Fig. 2 but for 30-day variability in OFES_NCEP (sum of first and second baroclinic modes). The magnitude of the energy flux is indicated by either the length of arrows (for ranges less than $0.002 \mathrm{~m}^{3} \mathrm{~s}^{-3}$ ) or thicker arrows with a constant length (for greater ranges).

\section{Reference}

Aiki, H., R. J. Greatbatch, and M. Claus, 2017: Towards a seamlessly diagnosable expression for the energy flux associated with both equatorial and mid-latitude waves. Prog. Earth Planet. Sci., 4, 11.

Andrews, D. G., J. R. Holton, and C. B. Leovy, 1987: Middle Atmosphere Dynamics. Academic Press, 489 pp.

Bühler, O., 2014: Waves and Mean Flows. Cambridge University Press.

Chatterjee, A., D. Shankar, J. P. McCreary, and P. N. Vinayachandran, 2013: Yanai waves in the western equatorial Indian Ocean. J. Geophys. Res., 118, 1556-1570.

Fukutomi, Y., and T. Yasunari, 2002: Tropical — extratropical interaction associated with the 10-25-day oscillation over the western Pacific during the Northern Summer. J. Meteor. Soc. Japan, 80, 311-331.

Fukutomi, Y., and T. Yasunari, 2013: Structure and characteristics of submonthly-scale waves along the Indian Ocean ITCZ. Climate Dyn., 40, 1819-1839.

Furuichi, N., T. Hibiya, and Y. Niwa, 2008: Model-predicted distribution of wind-induced internal wave energy in the world's oceans. J. Geophys. Res., 113, doi:10.1029/2008JC004768.

Gill, A., 1980: Some simple solutions for heat-induced tropical 
circulation. Quart. J. Roy. Meteor. Soc., 106, 447-462.

Greatbatch, R. J., M. Claus, P. Brandt, J. D. Matthießen, F. P. Tuchen, F. Ascani, ... and J. T. Farrar, 2018: Evidence for the maintenance of slowly varying equatorial currents by intraseasonal variability. Geophys. Res. Lett., 45, $1923-1929$.

Han, W., 2005: Origins and dynamics of the 90-day and 30-60day variations in the equatorial Indian Ocean. J. Phys. Oceanogr., 35, 708-728.

Horii, T., H. Hase, I. Ueki, and Y. Masumoto, 2008: Oceanic precondition and evolution of the 2006 Indian Ocean dipole. Geophys. Res. Lett., 35.

Horii, T., Y. Masumoto, I. Ueki, S. P. Kumar, and K. Mizuno, 2011: Intraseasonal vertical velocity variation caused by the equatorial wave in the central equatorial Indian Ocean. $J$. Geophys. Res., 116.

Hoskins, B. J., and D. J. Karoly, 1981: The steady linear response of a spherical atmosphere to thermal and orographic forcing. J. Atmos. Sci., 38, 1179-1196.

Hoskins, B. J., I. N. James, and G. H. White, 1983: The shape, propagation and mean-flow interaction of large-scale weather systems. J. Atmos. Sci., 40, 1595-1612.

Haynes, P. H., 1988: Forced, dissipative generalizations of finiteamplitude wave-activity conservation relations for zonal and nonzonal basic flows. J. Atmos. Sci., 45, 2352-2362.

Iskandar, I., W. Mardiansyah, Y. Masumoto, and T. Yamagata, 2005: Intraseasonal Kelvin waves along the southern coast of Sumatra and Java. J. Geophys. Res., 110.

Iskandar, I., T. Tozuka, H. Sasaki, Y. Masumoto, and T. Yamagata, 2006: Intraseasonal variations of surface and subsurface currents off Java as simulated in a high-resolution ocean general circulation model. J. Geophys. Res., 111.

Iskandar, I., Y. Masumoto, and K. Mizuno, 2009: Subsurface equatorial zonal current in the eastern Indian Ocean. $J$. Geophys. Res., 114.

Kindle, J. C., and J. D. Thompson, 1989: The 26- and 50-day oscillations in the western Indian Ocean: Model results. $J$. Geophys. Res., 94, 4721-4736.

Kinoshita, T., and K. Sato, 2013: A formulation of unified threedimensional wave activity flux of inertia-gravity waves and Rossby waves. J. Atmos. Sci., 70, 1603-1615.

Longuet-Higgins, M. S., 1964: On group velocity and energy flux in planetary wave motions. Deep Sea Research and Oceanographic Abstracts. Vol. 11, No. 1, Elsevier, 35-42.

Masumoto, Y., 2010: Sharing the results of a high-resolution ocean general circulation model under a multi-discipline framework - a review of OFES activities. Ocean Dyn., 60, 633-652.

Masumoto, Y., H. Sasaki, T. Kagimoto, N. Komori, A. Ishida, Y. Sasai, H. Sakuma, and co-authors, 2004: A fifty-year eddyresolving simulation of the world ocean: Preliminary outcomes of OFES (OGCM for the Earth Simulator). J. Earth Simulator, 1, 35-56.

Matsuno, T., 1966: Quasi-geostrophic motions in the equatorial area. J. Meteor. Soc. Japan, 44, 25-43.

Matthews, A. J., and G. N. Kiladis, 2000: A model of Rossby waves linked to submonthly convection over the eastern tropical Pacific. J. Atmos. Sci., 57, 3785-3798.

McCreary, J. P., 1984: Equatorial beams. J. Mar. Res., 42, 395430.

McCreary, J. P., and D. L. Anderson, 1984: A simple model of El
Niño and the Southern Oscillation. Mon. Wea. Rev., 112, 934-946.

Miyahara, S., 2006: A three dimensional wave activity flux applicable to inertio-gravity waves. SOLA, 2, 108-111.

Nagura, M., and M. J. McPhaden, 2010: Wyrtki jet dynamics: Seasonal variability. J. Geophys. Res., 115, C07009.

Niwa, Y., and T. Hibiya, 2004: Three-dimensional numerical simulation of M2 internal tides in the East China Sea. $J$. Geophys. Res., 109, doi:10.1029/2003JC001923.

Ogata, T., and Y. Masumoto, 2011: Interannual modulation and its dynamics of the mesoscale eddy variability in the southeastern tropical Indian Ocean. J. Geophys. Res., 116, C05005, doi:10.1029/2010JC006490.

Ogata, T., H. Sasaki, V. S. N. Murty, M. S. S. Sarma, and Y. Masumoto, 2008: Intraseasonal meridional current variability in the eastern equatorial Indian Ocean. J. Geophys. Res., 113, C07037, doi:10.1029/2007JC004331.

Ogata, T., M. Nagura, and Y. Masumoto, 2017: Mean subsurface upwelling induced by intraseasonal variability over the equatorial Indian Ocean. J. Phys. Oceanogr., 47, 1347-1365.

Orlanski, I., and J. Sheldon, 1993: A case of downstream baroclinic development over western North America. Mon. Wea. Rev., 121, 2929-2950.

Pacanowski, R. C., and S. M. Griffies, 1999: MOM 3.0 manual. GFDL Ocean Group Tech. Rep, 4, 680.

Plumb, R. A., 1986: Three-dimensional propagation of transient quasi-geostrophic eddies and its relationship with the eddy forcing of the time-mean flow. J. Atmos. Sci., 43, 16571678.

Rasmusson, E. M., and J. M. Wallace, 1983: Meteorological aspects of the El Niño/southern oscillation. Science, 222, 1195-1202.

Sasaki, H., M. Nonaka, Y. Masumoto, Y. Sasai, H. Uehara, and H. Sakuma, 2008: An eddy-resolving hindcast simulation of the quasiglobal ocean from 1950 to 2003 on the Earth Simulator. High Resolution Numerical Modelling of the Atmosphere and Ocean, Springer, New York, 157-185.

Schopf, P. S., and M. J. Suarez, 1988: Vacillations in a coupled ocean-atmosphere model. J. Atmos. Sci., 45, 549-566.

Sengupta, D., R. Senan, and B. N. Goswami, 2001: Origin of intraseasonal variability of circulation in the tropical central Indian Ocean. Geophys. Res. Lett., 28, 1267-1270.

Takaya, K., and H. Nakamura, 1997: A formulation of a waveactivity flux for stationary Rossby waves on a zonally varying basic flow. Geophys. Res. Lett., 24, 2985-2988.

Vinayachandran, P. N., N. H. Saji, and T. Yamagata, 1999: Response of the equatorial Indian Ocean to an unusual wind event during 1994. Geophys. Res. Lett., 26, 1613-1616.

Wakata, Y., 2007: Frequency-wavenumber spectra of equatorial waves detected from satellite altimeter data. J. Oceanogr., 63, 483-490.

Wheeler, M., and G. N. Kiladis, 1999: Convectively coupled equatorial waves: Analysis of clouds and temperature in the wavenumber-frequency domain. J. Atmos. Sci., 56, 374399.

Zebiak, S. E., 1982: A simple atmospheric model of relevance to El Niño. J. Atmos. Sci., 39, 2017-2027.

Manuscript received 20 July 2019, accepted 19 November 2019 SOLA: https://www.jstage.jst.go.jp/browse/solal 